\title{
Immediate Hypersensitivity Reactions Caused by Drug Excipients: A Literature Review
}

\author{
Caballero ML, Quirce S \\ Department of Allergy, La Paz University Hospital, IdiPAZ, Madrid, Spain
}

J Investig Allergol Clin Immunol 2020; Vol. 30(2): 86-100

doi: 10.18176/jiaci.0476

\begin{abstract}
The European Medicines Agency defines excipients as the constituents of a pharmaceutical form apart from the active substance. Immediate hypersensitivity reactions (IHRs) caused by excipients contained in the formulation of medications have been described. However, there are no data on the prevalence of IHRs due to drug excipients. Clinical manifestations of allergy to excipients can range from skin disorders to life-threatening systemic reactions.

The aim of this study was to review the literature on allergy to pharmaceutical excipients and to record the IHRs described with various types of medications, specifically reactions due to the excipients contained in their formulations. The cases reported were sorted alphabetically by type of medication and excipient in order to obtain a list of the excipients most frequently involved for each type of medication.

Key words: Allergy. Drug immediate hypersensitivity reaction. Excipient. Pharmaceutical excipients.
\end{abstract}

\section{Resumen}

La Agencia Europea de Medicamentos define los excipientes como los componentes de una forma farmacéutica diferenciados del principio activo. Se han descrito reacciones de hipersensibilidad inmediata causadas por los excipientes contenidos en la formulación de medicamentos. Sin embargo, no hay datos sobre la prevalencia de dichas reacciones. Las manifestaciones clínicas de la alergia a los excipientes pueden ir desde trastornos de la piel hasta reacciones sistémicas que ponen en peligro la vida.

El objetivo de este estudio fue realizar una revisión de la literatura sobre la alergia a los excipientes farmacéuticos y recopilar las reacciones inmediatas descritas con diferentes tipos de medicamento, debido solo a excipientes contenidos en sus formulaciones. Los casos se clasificaron alfabéticamente por tipo de medicamento y excipiente, con el fin de obtener una lista de los excipientes más frecuentemente implicados con cada tipo de medicamento.

Palabras clave: Alergia. Reacción de hipersensibilidad inmediata a medicamentos. Excipiente. Excipientes farmacéuticos. 


\section{Introduction}

The European Medicines Agency (EMA) defines excipients as the constituents of a pharmaceutical form apart from the active substance [1]. From the pharmaceutical point of view, an excipient is an inert substance added to a drug to change solubility or absorption kinetics, improve stability, influence palatability, or create a distinctive appearance. Some pharmaceutical excipients are foods or substances derived from foods (eg, casein, lysozyme), which could pose a threat to patients with food allergy [2,3]. Immediate hypersensitivity reactions (IHRs) to excipients may lead to a false-positive diagnosis of drug allergy [4].

The aim of this study was to review the literature on allergy to pharmaceutical excipients by using the electronic search engine PubMed/MEDLINE to identify potentially relevant studies published in peer-reviewed journals until October 2019. As a result, we present cases of IHRs to medications due to the excipients contained in their formulations. The cases were sorted alphabetically by type of medication and excipient in order to obtain a list of the excipients most frequently involved for each type of medication.

Table 1. Excipients Involved in Immediate Hypersensitivity Reactions Reported With Different Type of Medications

\begin{tabular}{|c|c|c|c|c|c|c|c|}
\hline \multirow{2}{*}{$\begin{array}{l}\text { Type of Medication } \\
\text { Analgesics }\end{array}$} & \multirow[b]{2}{*}{ Mannitol [9] } & \multirow[b]{2}{*}{ PVP [11] } & \multicolumn{2}{|l|}{ Excipient } & & & \\
\hline & & & & & & & \\
\hline Antibiotics & Macrogol 6000 [14] & PEGs + PS80 [15] & & & & & \\
\hline Chemotherapeutics & Cremophor [16] & PS80 [17] & & & & & \\
\hline Contrast media & $\mathrm{CMC}[18,19]$ & $\begin{array}{l}\text { Carrageenan } \\
{[20]}\end{array}$ & $\begin{array}{l}\text { Macrogol } \\
4000[21]\end{array}$ & PVP [22] & $\begin{array}{l}\text { Trometan } \\
{[23]}\end{array}$ & & \\
\hline Corticosteroids & CMC [27-37] & HG [38] & $\begin{array}{l}\text { Lactose } \\
{[25,39-41]}\end{array}$ & $\begin{array}{l}\text { Macrogols } \\
3350[42-45] \\
4000[46]\end{array}$ & $\begin{array}{l}\text { PS80 } \\
{[47]}\end{array}$ & $\begin{array}{l}\text { PVP } \\
{[48,49]}\end{array}$ & $\begin{array}{l}\mathrm{PG} \\
{[50,51]}\end{array}$ \\
\hline Dyspepsia medications & Macrogol 6000 [52] & Mannitol [10] & & & & & \\
\hline ESAs & PS80 [53] & & & & & & \\
\hline Insulin & Metacresol [55] & $\begin{array}{l}\text { Protamine } \\
{[57-59]}\end{array}$ & Zinc $[60,61]$ & $\begin{array}{l}\text { Protamine } \\
+ \text { zinc [62] }\end{array}$ & & & \\
\hline Laxatives & $\begin{array}{l}\text { Macrogols } 3350 \\
{[63,64] ; 4000[65,66]}\end{array}$ & & & & & & \\
\hline LTRAs & Aspartame [67] & & & & & & \\
\hline Mineral supplements & Casein [68] & $\begin{array}{l}\text { Macrogol } 6000 \\
{[14,69]}\end{array}$ & & & & & \\
\hline Monoclonal antibodies & PS20 $[70,71]$ & PS80 [73] & PS20 + PS80 & & & & \\
\hline Nasal decongestants & Lysozyme [75] & & & & & & \\
\hline NSAIDs & $\begin{array}{l}\text { Macrogols } 4000 \\
\text { and } 6000[76]\end{array}$ & Yellow dyes [77] & & & & & \\
\hline Ophthalmic products & BAC [79] & CMC [80] & PVP [81] & & & & \\
\hline Parenteral medications & $\mathrm{BnOH}[83-85]$ & & & & & & \\
\hline Perioperative settings & Gelatin [88-93] & HPMC [94] & $\begin{array}{l}\text { Mannitol } \\
\text { [95] }\end{array}$ & $\begin{array}{l}\text { PEG/analogs } \\
\text { (HES, POEPOPG, } \\
\text { PS80) }[72,96]\end{array}$ & $\begin{array}{l}\text { PVP } \\
{[97,98]}\end{array}$ & & \\
\hline Radiopharmaceuticals & Poloxamer 238 [100] & & & & & & \\
\hline Topical medications & $\begin{array}{l}\text { PEG/analogues } \\
\text { (Laureth-9) [101] }\end{array}$ & PVP $[102,103]$ & & & & & \\
\hline Throat lozenges & Lysozyme [104] & & & & & & \\
\hline Ultrasound gels & PEG [105] & & & & & & \\
\hline Vaccines & Aluminum [107] & Gelatin $[108,110]$ & PS80 [111] & & & & \\
\hline
\end{tabular}

Abbreviations: $\mathrm{BAC}$, benzalkonium chloride; $\mathrm{BnOH}$, benzyl alcohol; $\mathrm{CMC}$, carboxymethylcellulose; ESAs, erythropoiesis-stimulating agents; HES, hydroxyethyl starch; HG, hexylene glycol; HPMC, hydroxypropyl methylcellulose; LTRAs, leukotriene receptor antagonists; NSAIDs, nonsteroidal anti-inflammatory drugs; PEG, polyethylene glycol/macrogol; PG, propylene glycol; POEPOPG, poly(oxyethylene)-poly(oxypropylene) glycol; PS20, polysorbate 20; PS80, polysorbate 80; PVP, povidone. 


\section{IHRs due to Excipients Reported With Different Types of Medications}

The excipients involved in the IHRs described in this review article are shown in Tables 1 and 2. A link to the PubChem Database of the National Center for Biotechnology Information (NCBI-PCD) for the description of each excipient (Table 3) and a summary of the concentrations used to test each excipient (Table 4) are provided.

\section{Analgesics}

\section{Mannitol}

Intravenous mannitol is known to cause nonspecific hypersensitivity reactions [5-8]. Such manifestations are attributed to the hyperosmolar properties of mannitol, which can trigger nonspecific degranulation of mast cells and basophils [8]. Therefore, these reactions are usually considered to be nonimmunologic $[6,8]$. However, IHRs have been reported to occur after oral intake of mannitol-containing preparations, such as analgesics and sweeteners [9] and a dyspepsia medication [10].

IHRs with unrelated products due to mannitol [9] (Table 2) include urticaria and angioedema after treatment with a formulation of granular effervescent paracetamol (Tachipirina) and anaphylaxis after ingestion of coffee sweetened with a sweetener named Dietor. Both the Dietor and the Tachipirina formulations contained mannitol. The skin prick test (SPT) result to mannitol was negative whereas the intradermal test (IDT) result was positive. An oral challenge test (OCT) with a mannitol-containing oral laxative was positive.

\section{Povidone/Polyvinylpyrrolidone}

Anaphylaxis has been reported minutes after oral intake of acetaminophen (Doregrippin) [11]. Skin scratch tests with Doregrippin and povidone, also known as polyvinylpyrrolidone (PVP), were positive. Specific IgE (sIgE) to PVP was demonstrated by dot-blot.

\section{Antibiotics}

\section{Polyethylene Glycol/Macrogol}

Polyethylene glycol (PEG), also named macrogol, is reported with a numerical value. In the cosmetics industry, the number refers to the average number of ethylene oxide units in each molecule, whereas in the pharmaceutical industry, the number denotes the rounded, average molecular weight. Thus, the same compound may be named PEG-75

Table 2. Excipients Involved in Immediate Hypersensitivity Reactions Reported With Unrelated Products

\begin{tabular}{|c|c|}
\hline Type of product & Excipients \\
\hline Analgesic and sweetener & Mannitol [9] \\
\hline Antibiotic, mineral supplement, and throat lozenge & Macrogol $6000[14]$ \\
\hline Antibiotics, NSAIDs, and cosmetics & PEGs + PS80 [15] \\
\hline Chemotherapeutics and vitamins & Cremophor [16] \\
\hline Contrast media and corticosteroids & $\mathrm{CMC}[19]$ \\
\hline Dyspepsia medication, topical corticosteroids, and antibiotic & Macrogol $6000[52]$ \\
\hline Laxative, sunscreen cream, and toothpaste & Macrogol $3350[63]$ \\
\hline NSAIDs, analgesic, bath soap, and shaving cream & Macrogols 4000 and 6000 [76] \\
\hline Ophthalmic product and corticosteroids & $\mathrm{CMC}[80]$ \\
\hline Perioperative settings and aspic & Gelatin [88] \\
\hline Perioperative settings, vaccines, and beef meat & Gelatin [91] \\
\hline Perioperative settings, dairy products, and meat species & Gelatin ( $\alpha$-gal) [93] \\
\hline Perioperative settings, shampoo, and plasma expander & PEG/analogues (HES, POEPOPG, PS80) [72] \\
\hline Perioperative settings, antiepileptic, antiplatelet agents, and wound dressing & PEGs/analogues (PS80) [96] \\
\hline Topical medication, antihistamine, soap, moisturizing creams, and toothpaste & PEG/analogues (Laureth-9) [101] \\
\hline Topical medication and hair care products & PVP [103] \\
\hline Throat lozenges, cured cheese, and raw egg & Lysozyme [104] \\
\hline Vaccines and colchicum & Aluminum [107] \\
\hline Vaccines and gelatin & Gelatin [108] \\
\hline Vaccines and gelatinous candies & Gelatin [109] \\
\hline
\end{tabular}

Abbreviations: CMC, carboxymethylcellulose; HES, hydroxyethyl starch; NSAIDs, nonsteroidal anti-inflammatory drugs; PEG, polyethylene glycol/ macrogol; POEPOPG, poly(oxyethylene)-poly(oxypropylene) glycol; PS80, polysorbate 80; PVP, povidone. 
or PEG-3350, depending on the product type [12]. PEGs are used as excipients but are also active ingredients of laxatives and bowel preparations [13].

\section{Macrogol 6000}

IHRs with unrelated products due to macrogol 6000 [14] (Table 2) include generalized urticaria, tachycardia, and dizziness after ingestion of a tablet of phenoxymethylpenicillin (V-Pen mega). The patient had previously experienced urticaria after ingestion of a fluoride tablet (Fludent) and sucking a throat tablet (Bafucin). SPTs to both tablets and macrogol 6000 (ingredient common in all 3 products) were positive.

\section{PEG/Macrogol and Polysorbate 80}

IHRs with unrelated products due to PEGs and polysorbate (PS) 80 [15] (Table 2) include episodes of urticaria after intake of antibiotics (amoxicillin-clavulanic acid and ciprofloxacin tablets), nonsteroidal anti-inflammatory drugs (ketoprofen granules and diclofenac tablets), and after using PEGcontaining cosmetics [15]. All medications contained PEGs of different molecular weights (400, 4000, and 6000) and PS80. SPTs were positive to the 3 PEGs and PS80, although the result of the basophil activation test (BAT) with the PEGs and PS80 were negative [15].

\section{Chemotherapeutics}

\section{Cremophor}

IHRs with unrelated products due to cremophor [16] (Table 2): A patient experienced anaphylaxis after chemotherapy with paclitaxel (Taxol). The treatment was changed to an etoposide, and the patient experienced cough, chest discomfort, dyspnea, and sweating. Two weeks later, the patient developed anaphylaxis with a multivitamin supplement. A request to the manufacturers provided the list of components of Taxol and the multivitamin solution, and cremophor was identified as the

Table 3. Links to the PubChem Database of the National Center for Biotechnology Information (NCBI-PCD) for the Description of the Excipients Involved in the Immediate Hypersensitivity Reactions Reported

\begin{tabular}{|c|c|}
\hline Excipients & \\
\hline Aspartame & https://pubchem.ncbi.nlm.nih.gov/compound/134601 \\
\hline Benzalkonium chloride & https://pubchem.ncbi.nlm.nih.gov/compound/13740 \\
\hline Benzyl alcohol & https://pubchem.ncbi.nlm.nih.gov/compound/244 \\
\hline Carboxymethylcellulose & https://pubchem.ncbi.nlm.nih.gov/compound/24748 \\
\hline Carrageenan & https://pubchem.ncbi.nlm.nih.gov/compound/6850766 \\
\hline Casein & https://pubchem.ncbi.nlm.nih.gov/compound/73995022 \\
\hline Cremophor & https://pubchem.ncbi.nlm.nih.gov/compound/104840 \\
\hline Gelatin & https://pubchem.ncbi.nlm.nih.gov/substance/176259305 \\
\hline Hexylene glycol & https://pubchem.ncbi.nlm.nih.gov/compound/7870 \\
\hline Hydroxyethyl starch & https://pubchem.ncbi.nlm.nih.gov/compound/16213095 \\
\hline Hydroxypropyl methylcellulose & https://pubchem.ncbi.nlm.nih.gov/compound/24832095 \\
\hline Lactose & https://pubchem.ncbi.nlm.nih.gov/compound/84571 \\
\hline Laureth-9 & https://pubchem.ncbi.nlm.nih.gov/compound/24750 \\
\hline Lysozyme & https://pubchem.ncbi.nlm.nih.gov/compound/131750181 \\
\hline Mannitol & https://pubchem.ncbi.nlm.nih.gov/compound/6251 \\
\hline Metacresol & https://pubchem.ncbi.nlm.nih.gov/compound/342 \\
\hline Poloxamer 238 & https://pubchem.ncbi.nlm.nih.gov/compound/Poloxalene \\
\hline Polyethylene glycol/macrogol & https://pubchem.ncbi.nlm.nih.gov/compound/174 \\
\hline Poly(oxyethylene)-poly(oxypropylene) glycol & https://pubchem.ncbi.nlm.nih.gov/compound/10154203 \\
\hline Polysorbate 20 & https://pubchem.ncbi.nlm.nih.gov/compound/443314 \\
\hline Polysorbate 80 & https://pubchem.ncbi.nlm.nih.gov/compound/5284448 \\
\hline Povidone & https://pubchem.ncbi.nlm.nih.gov/compound/6917 \\
\hline Propylene glycol & https://pubchem.ncbi.nlm.nih.gov/compound/1030 \\
\hline Quinoline yellow & https://pubchem.ncbi.nlm.nih.gov/compound/24671 \\
\hline Sunset yellow & https://pubchem.ncbi.nlm.nih.gov/compound/17730 \\
\hline Trometamol & https://pubchem.ncbi.nlm.nih.gov/compound/6503 \\
\hline
\end{tabular}




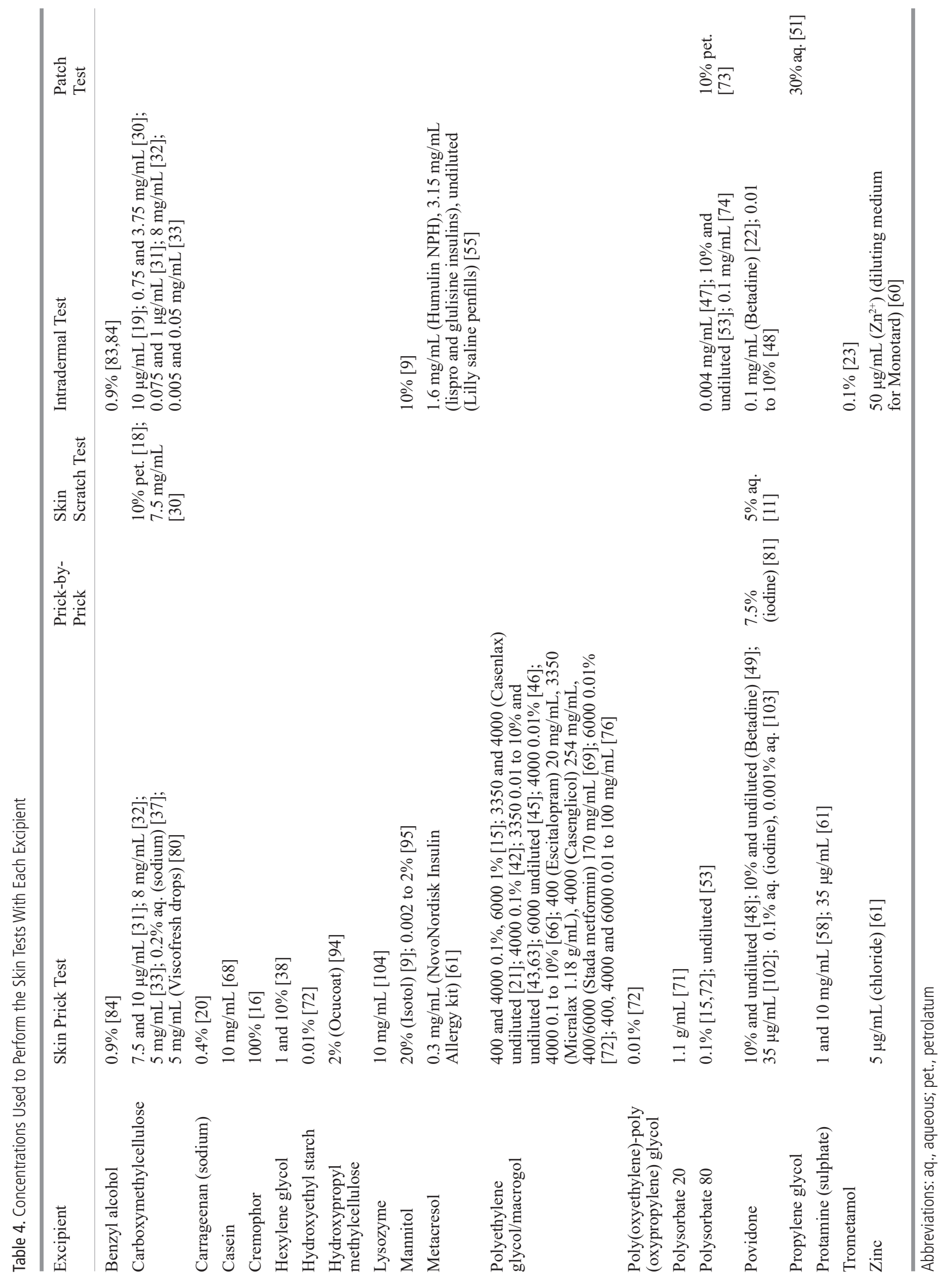


common excipient. The etoposide contained polysorbate. SPTs with cremophor and polysorbate were positive, suggesting potential cross-reactivity between these structurally related polymers and PEG [12].

\section{PS80}

PS80 was suspected as the causative agent in an episode of anaphylaxis during chemotherapy with an etoposide [17]. An indirect study was performed with a PS80-free etoposide (VePesid), etoposide (Sandoz), and docetaxel (Actavis) (PS80containing). SPTs were negative to all preparations, whereas IDTs were positive to the 2 PS80-containing preparations.

\section{Contrast Media}

\section{Carboxymethylcellulose}

There are 2 reports of IHRs due to carboxymethylcellulose (CMC), as follows:

- Anaphylaxis with a barium sulfate suspension (CMCcontaining) [18]: Skin scratch tests were positive with the suspension and with CMC.

- IHRs with unrelated products due to CMC [19] (Table 2): Anaphylaxis with the barium sulfate suspension Micropaque Colon was reported in a patient who had previously experienced episodes of malaise after intraarticular infiltrations with CMC-containing corticosteroids. SPTs were positive to the suspension and negative to $\mathrm{CMC}$, although the IDT to $\mathrm{CMC}$ was positive $(10 \mu \mathrm{g} / \mathrm{mL})$. Both BAT and the cysteinyl-leukotriene release test to $\mathrm{CMC}$ were positive. Dot-blot revealed sIgE to CMC.

\section{Carrageenan}

Anaphylaxis with a sodium carrageenan-containing suspension (Liquid Polibar) [20]: SPTs were positive both to the suspension and to sodium carrageenan. A radioallergosorbent test (RAST) revealed sIgE to sodium carrageenan.

\section{Macrogol 4000}

Anaphylaxis with SonoVue, which contains macrogol 4000: SPTs to SonoVue and macrogols 3350 and 4000 were positive [21].

\section{PVP}

Asthma induced by an ioxitalamate preparation (Telebrix Hystero), an iodinated contrast medium containing PVP. The results of IDT, BAT, and the leukocyte histamine release test were positive to PVP [22].

\section{Trometamol}

IHR to a preparation of gadoteridol (Prohance), a gadolinium-based contrast agent (GBCA): SPTs and IDTs were performed with Prohance and 2 other GBCAs, gadobutrol (Gadovist) and gadoterate meglumine (Dotarem). All SPTs were negative. IDTs were positive to Prohance and Gadovist and negative to Dotarem. Prohance and Gadovist contain trometamol. The IDT to trometamol yielded a positive result [23].

\section{Corticosteroids}

Although true corticosteroid allergy is uncommon, there is growing evidence of IHRs due to excipients contained in corticosteroid preparations that occur more frequently than to corticosteroids themselves. Notwithstanding, excipient testing is frequently overlooked [24]. A literature review on IHRs to corticosteroids disclosed 120 reactions that were reported in 106 patients (2-90 years) [25]. Excipients were responsible for $28.3 \%$ of the reactions. Lactose was involved in 10 reactions (8 anaphylaxis and 2 urticaria/angioedema), CMC in 7 (all anaphylaxis), and PEG in 5 (all anaphylaxis). Reactions induced by excipients contained in corticosteroid formulations, such as lactose and $\mathrm{CMC}$, have been demonstrated by SIgE to these excipients [26]. In a recent study of 64 patients who underwent corticosteroid allergy testing, true allergy was confirmed in 9 patients (14\%), 5 of whom had positive SPT or provocation test results. The patients were actually allergic to the excipients (CMC and PEG), thus highlighting the importance of an accurate diagnosis, for which the authors propose a diagnostic algorithm to identify corticosteroid allergy [24].

\section{CMC}

There are several reports of anaphylaxis due to $\mathrm{CMC}$, as follows:

- The first 2 reported cases occurred after intraarticular injections [27]. SPTs were positive to CMC. No cross-reactivity with hydroxypropyl cellulose was demonstrated.

- Reactions were observed in 2 patients after intradermal injection of triamcinolone acetonide (Kenalog) [28,29]. SPTs to CMC were positive in both patients. In one of the patients, sIgE was also detected by immunoassay and dot-blot [28].

- Three cases were recorded after injection of triamcinolone acetonide (Kenacort-A) [30,31]. Tests with CMC were positive in all patients.

- Three cases were recorded after injection of triamcinolone acetonide (Trigon depot). SPT to CMC was negative in 1 case, whereas the IDT was positive [32]. The other 2 cases were confirmed by positive SPTs [33].

- Reaction after intraarticular injection of triamcinolone acetonide (Triamcort depot). The result of SPT to Triamcort was negative, whereas the IDT was positive. The patient tolerated a cumulative dose of sodium CMC $(250 \mathrm{mg})$ in an OCT [31].

- Reaction after injection of betamethasone dipropionate (Diprophos) [31]. SPTs to Diprophos and triamcinolone acetonide (Kenacort) were weakly positive, whereas IDTs were positive. An SPT to CMC was equivocal whereas the IDT was positive. The patient tolerated a cumulative dose of $250 \mathrm{mg}$ sodium CMC in the OCT. A dot-blot to detect sIgE was negative.

- Reaction after an intradermal triamcinolone acetonide injection [34]. The SPT result was positive to CMC. 
- IHRs were recorded in 2 patients after intraarticular and intralesional injections of cortivazol (Altim) [35]. SPTs and IDTs were positive to CMC. An oral CMCcontaining amphotericin B suspension (Fungizone) was tolerated by both patients, thus confirming that this molecule is not absorbed through the digestive system, as reported elsewhere [36].

- Anaphylaxis after intraarticular injection of triamcinolone acetonide (Adcortyl) [37]. The result of the SPT to Adcortyl was negative, whereas the IDT was positive. SPTs with the components provided by the manufacturer proved to be positive to $\mathrm{CMC}$.

\section{Hexylene Glycol}

Angioedema and dyspnea have been recorded after topical application of a mometasone furoate cream. An open provocation test was positive with mometasone furoate cream and ointment, and a positive reaction was observed to pure hexylene glycol (Sigma-Aldrich), which is a common ingredient of both mometasone formulations, in 1\% and 10\% concentrations by prick and rub tests [38].

\section{Lactose}

Lactose was responsible for IHRs to corticosteroids in 10 patients (3-15 years) with cow's milk allergy [25]. Nine patients reacted to intravenous methylprednisolone sodium succinate (Solu-Medrol) $40 \mathrm{mg} / \mathrm{mL}$, which contains lactose as an excipient. Analysis revealed that the lactose was contaminated by $\beta$-lactoglobulin as a result of imperfect purification [39]. The remaining patient, who previously tolerated inhaled fluticasone and salmeterol (Advair Diskus), developed anaphylaxis to a different batch of the same medication that was found to contain lactose [40]. Therefore, in patients with cow's milk allergy, special attention should be paid to ensure the prescribed medication does not contain lactose [25,39].

Anaphylaxis was reported in a boy with cow's milk allergy after treatment with a budesonide dry powder inhaler (lactosecontaining) [41]. Mass spectrometry revealed no traces of milk proteins. However, analysis revealed the presence of galabiose, an oligosaccharide with an $\alpha$-gal-like structure differing only in the glycosidic bond. Whereas $\alpha$-gal is a $[\operatorname{Gal}(\alpha 1-3)$ Gal], galabiose is a $[\mathrm{Gal}(\alpha 1-4) \mathrm{Gal}]$ saccharide. Given the impossibility of determining SIgE to galabiose or galactooligosaccharides, $\alpha$-gal sIgE was determined by ImmunoCAP, and the result was positive.

\section{PEG/Macrogol}

PEGs were involved in reactions to corticosteroids in 5 cases (all anaphylaxis) [25]. One patient developed acute angioedema during an OCT [42], and another patient experienced anaphylaxis during an IDT [43]. The authors highlighted the need to avoid PEG-containing medications in patients sensitive to PEG through any route.

\section{Macrogol 3350}

Anaphylaxis was recorded following intraarticular or intramuscular injection of methylprednisolone acetate
(Depo-Medrol), with evidence of sensitization to macrogol 3350 [42-45].

\section{Macrogol 4000}

Anaphylaxis was recorded after intraarticular injection of betamethasone (Diprostene) containing macrogol 4000 [46]. SPT and IDT results to macrogol 4000 were positive.

\section{PS80}

Two patients developed IHRs after intramuscular injection of the corticosteroid Inzitan (which contains dexamethasone and cyanocobalamin). In one patient the reaction occurred after the seventh dose and in the other after the first dose [47]. IDTs to PS80 were positive in both patients. An OCT with PS80 was performed in the second patient, who tolerated a dose corresponding to that contained in the Inzitan vial. The authors suggested that this negative result indicated that PS80 was not absorbed orally.

\section{PVP}

- IHR was recorded after intraarticular administration of mepivacaine hydrochloride and paramethasone acetate (PVP-containing). In vitro studies (histamine release, basophil degranulation, and lymphoblast transformation tests) with PVP were negative. The results of provocation testing (SPT, IDT, subcutaneous, and intramuscular) were only positive after intramuscular administration of the pure PVP preparation $(1 \mathrm{~mL})$ [48].

- Asthma and rhinitis have been recorded after administration of prednisolone oral solution (Estilsona). An OCT with the solution was positive. SPT was positive to PVP [49].

\section{Propylene Glycol}

Propylene glycol (PG) was the excipient most frequently found in topical corticosteroid preparations (64\% of products analyzed [106 of 166]) [50]. A retrospective analysis performed in the USA (1996 to 2006) showed that 810 of 23359 (3.5\%) patients had a positive patch test result to PG. In $18.3 \%$ of cases, these were due to topical corticosteroid preparations [51].

\section{Dyspepsia Medications}

\section{Macrogol 6000}

IHRs have been reported with unrelated products due to macrogol 6000 [52] (Table 2). Anaphylaxis occurred after the intake of a betaine citrate effervescent tablet (UPSA), containing macrogol 6000. Immediate contact urticaria has been reported after using betamethasone valerate and diflucortolone valerate creams (Betneval and Nerisone, respectively). The patient presented previous maculopapular exanthema after oral intake of bacampicillin (Penglobe). SPTs to both creams were positive. The common ingredient was macrogol. SPTs to PEG-300 and PEG-1500 were positive. An OCT with betaine citrate (Beaufour), which is macrogol-free, was negative. 


\section{Mannitol}

Anaphylaxis was reported after the intake of a chewable tablet of mannitol-containing cisapride (Cisapid MPS) [10]. SPTs with the tablet and D-mannitol were positive. sIgE to mannitol was demonstrated by ELISA. Mannitol was not reported on the package insert of Cisapid MPS.

\section{Erythropoiesis-Stimulating Agents}

\section{PS80}

IHRs to recombinant erythropoietin and darbepoetin due to PS80 [53] include the following 2 cases:

- Generalized pruritus, erythema, and orofacial angioedema after subcutaneous administration of recombinant erythropoietin (Eprex) (PS80-containing). IDT to undiluted PS80 was positive. SPTs, IDTs, and a challenge test with a PS-free preparation of erythropoietin were negative.

- Urticaria, pruritus, and orofacial angioedema after the third dose of darbepoetin (Aranesp) (PS80-containing). SPTs and IDTs with Aranesp, PS80, and PS-free Eprex indicated that PS80 was involved in the reaction.

\section{Insulin}

The prevalence of IHRs to insulin products is around $2 \%$, and less than one-third of cases are related to insulin itself. Most reactions were due to excipients (metacresol, protamine, and zinc) [54].

\section{Metacresol}

IHRs after treatment with various insulins, isophane (Protaphane), aspart, Humulin neutral protamine Hagedorn (NPH), glargine, and detemir [55]: IDTs performed with these and other available insulin preparations elicited erythema, urticaria, and eventual rapid skin breakdown. Analysis of the ingredients showed metacresol to be the common excipient. The authors commented on the specific nature of the skin reaction, which involved urticaria, pain, and excoriation with abrasion and/or epidermal separation within 5 minutes of injection and had not previously been described. They concluded that this is the first documented case of metacresol allergy successfully treated with desensitization therapy.

\section{Protamine}

NPH insulins contains protamine to prolong metabolism, leading to a longer therapeutic effect than with regular insulins [56].

There are several reports of IHRs due to Protamine, as follows:

- Generalized urticaria and facial angioedema 5 minutes after injection of NPH insulin (bovine origin): IDTs to protamine sulphate (Sigma-Aldrich) and NPH insulin were positive [57].

- IHRs in 2 patients (anaphylaxis/ generalized urticaria) after injection of NPH human insulin injection: SPTs to NPH insulin and protamine were positive for both patients. In vitro assays showed elevated $\operatorname{IgE}$ and $\mathrm{IgG}$ levels to protamine [58].
- Insulin desensitization due to hypersensitivity to regular and NPH insulins [59]: The patient required insulin desensitization for severe urticaria, angioedema, and occasional wheezing resulting from her insulin dose. She underwent a standard protocol with regular Humulin insulin twice in a 2-month period, although her symptoms persisted. She was found to have high levels of $\operatorname{sIgE}$ to protamine and insulin. Dual desensitization to both regular and NPH insulins resulted in an improvement in the patient's condition.

\section{Zinc}

Zinc is used with protamine to develop slow-release insulin [54]. Reactions have been reported, as follows:

- Immediate generalized urticaria when changing from shortto intermediate-acting insulins (Actrapid to Monotard [porcine insulin]): The same reaction was observed with human semisynthetic monocomponent insulin (Monotard HM). IDTs were negative to bovine, porcine, and human insulins, but positive to diluting medium for Monotard (zinc-containing) and to zinc acetate [60].

- Injection site reactions and generalized urticaria, facial edema, and dyspnea, 1 hour after injection of NPH insulin: Treatments with Actrapid and detemir insulin (Levemir) induced the same manifestations. SPT was positive to zinc chloride [61].

\section{Protamine and Zinc}

Cutaneous generalized reaction after injection of shortacting and regular insulin and later monocomponent porcine insulin (Monotard). IDTs were negative for bovine, porcine, and human insulin but strongly positive to zinc acetate and diluting medium for Monotard. The patient was then treated with Humulin NPH (low zinc content), although reactions reappeared. SPTs were then positive to zinc and protamine [62].

\section{Laxatives}

\section{Macrogol 3350}

- IHRs have been reported with unrelated products due to macrogol 3350 [63] (Table 2). These involved anaphylaxis after intake of a laxative solution during bowel preparation and reactions after application of a sunscreen and with the use of a toothpaste, all of which were PEG-containing products. SPTs were positive to PEG-9000 and PEG-3350.

- Anaphylaxis during bowel preparation with PEG-3350 tablets (HalfLytely) [64].

\section{Macrogol 4000}

- Two cases of urticaria and angioedema after the intake of an evacuant solution (Bohm) have been reported. SPTs to the solution were negative whereas the OCTs with the solution and PEG-4000 were positive. The results of the IDTs were positive to PEG-4000 [65].

- Consecutive anaphylaxis episodes were reported after the intake of 2 bowel preparations containing PEG- 
4000 (Selg for the first colonoscopy and Lovol-esse for the rescheduled colonoscopy) [66]. SPT to macrogol 4000 was positive. The patient reported rapid onset of generalized urticaria after intake of a capsule of nimesulide (Mesulid), which contained cetomacrogol 1000 (polyethylene glycol family).

\section{Leukotriene Receptor Antagonists}

\section{Aspartame}

Systemic dermatitis after starting treatment with chewable montelukast tablets (Singulair) [67]. SPTs were positive to several chemicals, including formaldehyde. The patient's mother noticed that aspartame, which is metabolized to formaldehyde, was reported in the package insert of Singulair.

\section{Mineral Supplements}

\section{Casein}

A systemic reaction was reported in a child allergic to cow's milk after intake of the first dose of a preparation of iron protein succinylate (Ferplex 40) [68]. The source of protein was not specified, although the manufacturer confirmed it to be casein ( $575 \mathrm{mg} / \mathrm{vial})$. IgE-immunoblotting showed a strong signal to Ferplex and a $35-\mathrm{kDa}$ band in the casein extract. The induction of a reaction after the first dose indicates that the source protein should be clearly indicated in the package insert.

\section{Macrogol 6000}

- IHR after ingestion of a sodium fluoride tablet (Fludent) [14]. SPTs to the tablet and macrogol 6000 yielded positive results: The patient reported contact urticaria after use of a cetomacrogol-containing emollient cream (Aqualan). The SPT to the cream was positive.

- Anaphylaxis after the first intake of a potassium bicarbonate effervescent tablet (Boi-K), which contains macrogol 6000 [69]: The patient reported symptoms after topical use of macrogol-containing cosmetics. The result of an SPT to the tablet dissolved in water was negative. The results of SPTs to other macrogol-containing medications were positive. An OCT with one-quarter of the tablet elicited an immediate reaction. Dot-blot yielded a positive result to 3 medications containing macrogols of different molecular weights, namely, 6000 (Boi-K), 4000 (Casenglicol), and 400 (Atarax). The amount of macrogol 6000 present in the Boi-K tablet was not reported in the package insert. Only Casenglicol provides complete information on its macrogol content.

\section{Monoclonal Antibodies}

PS20

- IHRs caused by omalizumab (Xolair) injections in 2 patients after more than a year of uneventful treatment [70]: One of the patients developed ocular angioedema and generalized pruritus to polysorbatecontaining eye drops several months after the reaction to omalizumab. IDT to Xolair was positive for this patient. For the other patient, both the SPT and the IDT results were negative, although after treatment with Xolair, IDT to polysorbate was positive.

- Anaphylaxis after the first injection of omalizumab (Xolair) [71]: SPTs to Xolair and PS20 (main excipient) were positive. It was not possible to test omalizumab IgG1 alone, although testing of other monoclonal antibodies (fully human [adalimumab, golimumab], humanized [tocilizumab, certolizumab], and chimeric [rituximab, infliximab]) yielded positive results. PS20 was the common excipient, except in certolizumab, which in its commercialized form (Cimzia) contains PEG/macrogol (cross-reactive with PS) [72]. SPTs with macrogol 3350 (Colopeg) and macrogol 4000 (Forlax) were performed to confirm whether the positive SPT result to Cimzia was due to PEG. The results were positive for both, as was the case for Xolair and PS20.

PS80

Reactions to adalimumab (Humira) and ustekinumab (Stelara) [73]: The patient developed generalized wheals and pruritus after adalimumab injections. When therapy was switched to ustekinumab, the patient experienced severe urticarial symptoms after each injection. PS80 was the common excipient in both preparations. The result of the SPT to PS80 was positive.

\section{PS20 and PS80}

Erythematous injection site reactions have been reported after therapy with proprotein convertase subtilisin/kexin type 9 inhibitor (PCSK9i) and with the human monoclonal antibodies alirocumab (Praluent) and evolocumab (Repatha) [74]. The 2 PCSK9i formulations contained PS20 (Praluent) and PS80 (Repatha). The patient experienced a positive reaction during IDT with PS80 $(0.1 \mathrm{mg} / \mathrm{mL})$.

\section{Nasal Decongestants}

Lysozyme

IHR to the lysozyme-containing nasal decongestant Narlisim was reported in a child whose diet did not include egg at the time of the reaction [75]. SPTs to egg yolk and white and Narlisim were all positive. The sIgE was positive to egg yolk and white, ovalbumin, ovomucoid, and lysozyme. The allergen microarray revealed a positive sIgE result to Gal d 4 (lysozyme).

\section{Nonsteroidal Anti-inflammatory Drugs}

\section{Macrogols 4000 and 6000}

IHRs to unrelated products due to macrogols 4000 and 6000 [76] (Table 2): The reactions occurred a few minutes after the intake of nimesulide granules containing macrogol 4000 , with paracetamol syrup (Tachipirina) which also contains 
macrogol 6000, and when using some types of bath soap and shaving cream. The results of SPTs and BATs to macrogols 4000 and 6000 were positive, as were the results of SPTs with Tachipirina.

\section{Yellow Dyes: Quinoline Yellow and Sunset Yellow}

Three cases of urticaria have been reported after the intake of enteric-coated aspirin containing yellow dyes (Cartia) [77].

\section{Ophthalmic Products}

The allergenicity of preservatives in topical ophthalmic medications should not be underestimated, even though associated reactions are rare [78].

\section{Benzalkonium Chloride}

Two anaphylaxis episodes were reported after the use of eye-drops and after receiving mydriatic drops. Benzalkonium chloride (BAC) was identified as the common excipient in both products [79]. SPT and IDT results were positive to BAC.

\section{CMC}

IHRs have been reported with unrelated products due to $\mathrm{CMC}$ [80] (Table 2). A patient developed conjunctival erythema and bilateral periocular edema with urticarial lesions after application of CMC-containing drops (Viscofresh). The patient had previously experienced generalized urticaria appeared after a CMC-containing infiltration (Trigon Depot). The results of SPTs with both products and dot-blot with the Viscofresh drops were positive.

\section{PVP}

The first case of anaphylaxis to PVP as an excipient in an ophthalmic preparation was recently reported [81]. Immediately after administration of corticosteroid eye drops ( 1 drop in both eyes), the patient developed periorbital swelling, angioedema of the tongue and lips, dyspnea with a sensation of nasal obstruction, and throat constriction. The results of prick-by-prick tests with the eye drops and PVP-iodine $7.5 \%$ antiseptic solution, were positive.

\section{Parenteral Medications}

\section{Benzyl Alcohol}

Benzyl alcohol $(\mathrm{BnOH})$ is used as a bacteriostatic preservative in intravenous medications and topical drugs [82] and can cause sensitization both by contact and systemically [4].

- Anaphylaxis after injections of $\mathrm{BnOH}$-containing vitamin B12 (cyanocobalamin) [83,84]: SPTs to preparations of $\mathrm{BnOH}$-containing cyanocobalamins were negative whereas IDTs were positive.

- Systemic reaction on 3 occasions after administration of BnOH-preserved cytarabine, vincristine, and heparin solutions: SPT to $\mathrm{BnOH}$ was positive [85].

\section{Perioperative Settings}

In recent years, given the emergence of IHRs to a number of hidden allergens, excipients should be given special consideration in all patients who experience perioperative hypersensitivity reactions [86].

\section{Gelatin}

Gelatin in colloids has been implicated in $0.34 \%$ of cases of perioperative anaphylaxis [87].

Intraoperative anaphylaxis has been reported with topical gelatin-based hemostatic products, as follows:

- IHRs with unrelated products due to gelatin [88] (Table 2): Anaphylaxis occurred after application of Gelfoam, which contains porcine gelatin. Reactions had previously been described after ingestion of Spam (canned pork meat with a gelatinous glaze, also known as aspic). SPT and sIgE to porcine gelatin were positive. As part of the preoperative assessment, the authors recommended inquiring about gelatin allergy not only in drugs, but also in food.

- Anaphylaxis after injection of Gelfoam: sIgE determinations were positive to porcine and bovine gelatins [89].

- Anaphylaxis after application of Gelfoam and Floseal (which contains bovine gelatin): sIgE was positive to porcine gelatin, but negative to bovine gelatin. SPT was positive to a mix of both bovine and porcine gelatins. SPT to reconstituted Floseal was negative, although this negative result is uncertain, since the product is a matrix that does not penetrate the epidermis. Given concern over potential anaphylaxis, IDT with Floseal was not performed. A subsequent test revealed sIgE to bovine gelatin [90].

- IHRs with unrelated products due to gelatin [91] (Table 2): Anaphylaxis occurred after injection of Floseal in a patient who had previously experienced anaphylaxis after administration of gelatin-containing vaccines and facial rash after eating beef. A postoperative study revealed SIgE to bovine gelatin.

- Anaphylaxis after Floseal injection: A postoperative study demonstrated sIgE to bovine gelatin [92].

- Anaphylaxis after application of SurgiFlo, which contains porcine gelatin: The study revealed sIgE to porcine gelatin [92].

- IHRs with unrelated products due to gelatin [93] (Table 2): Anaphylaxis occurred after infusion of Gelofusin, which contains bovine gelatin, in a patient who had previously developed urticaria related to consumption of dairy products and meat species (pork and beef). SPTs and sIgE determinations were performed with mammalian meats, milk and its components, bovine serum albumin, oligosaccharide galactose- $\alpha$-1,3-galactose ( $\alpha$-gal), and Gelofusin. The results were positive to meats (pork, beef, lamb, and horse), milk, $\alpha$-gal, and Gelofusin. This case highlights the fact that patients sensitized to $\alpha$-gal moieties from mammalian meat may react to mammalian gelatin and gelatin-containing drugs. 


\section{Hydroxypropyl Methylcellulose}

Anaphylaxis was reported during two cataract surgeries [94]. The patient was studied with the drugs used in both procedures, and SPTs yielded positive results to Occucoat and Xylocaine gel, both of which contain hydroxypropyl methylcellulose.

\section{Mannitol}

IHRs to intravenous paracetamol/acetaminophen are rare. However, episodes of anaphylaxis caused by perioperative Perfalgan (which contains mannitol) were reported in 2 patients, both of whom tolerated paracetamol/acetaminophen [95]. IDTs to Perfalgan and mannitol were positive.

\section{PEG/Macrogol and Structural Analogues: Hydroxyethyl Starch, Poly(oxyethylene)- poly(oxypropylene) Glycol, and PS80}

- IHRs with unrelated products due to PEG and PS80, with cross-reactivity to hydroxyethyl starch (HES) and Poly(oxyethylene)-poly(oxypropylene) glycol (POEPOPG) [72] (Table 2): Anaphylaxis after application of PVP-iodine gel in a patient who had previously developed wheezing with a shampoo. SPTs were performed with the constituents of PVP-iodine gel and shampoo. Results were positive for POEPOPG, PS80, and PEG-6000. As these components have a common structure $[(\mathrm{CH} 2 \mathrm{CH} 2 \mathrm{O}) n]$, reactions were attributed to these PEG analogs. Months later, a new episode of intraoperative anaphylaxis occurred in the same patient. The subsequent work-up revealed that the HES-containing plasma expander (Hespander) used during surgery had a chemical moiety similar to the structure of PEG. SPTs to both the plasma expander and HES were positive.

- IHRs with unrelated products due to PEGs with cross-reactivity to PS80 [96] (Table 2): Perioperative anaphylaxis followed by other anaphylaxis episodes to unrelated drugs as valproate (Deprakine), clopidogrel (Grepid), and levetiracetam, and with application of colored chlorhexidine (PS80-containing) and a Mepilex bandage. PEGs were identified in Deprakine and Grepidand and as hidden ingredients of the Mepilex bandage. SPTs were positive to PEG-6000 and PEG3000 , colored chlorhexidine, PS80, and the inner and outer surfaces of the Mepilex bandage.

PVP

- Anaphylaxis after application of PVP-iodine (Betadine) to a surgical wound: The results of SPTs, IDTs, and BATs were positive to PVP-iodine and PVP. PVP-iodine is a skin antiseptic, although this case illustrates the risk of passage to the bloodstream after application to a surgical wound [97].

- Anaphylaxis after application of PVP-iodine (Videne) to a surgical wound: The SPT was positive to PVP-iodine. This case confirms the importance of considering PVPiodine and other antiseptics when investigating possible causes of perioperative anaphylaxis [98].

\section{Radiopharmaceuticals}

\section{Poloxamer 238}

Poloxamers are a family of amphiphilic polymers of hydrophilic ethylene oxide and hydrophobic propylene oxide [99] or PEG-PG copolymers [12].

Anaphylaxis occurred after intravenous administration of Nanocoll [100]. SPTs and IDTs to poloxamer 238 were positive.

\section{Topical Medications}

\section{PEG/Macrogol and Structural Analogues: Laureth-9}

IHRs have been reported with unrelated products due to PEG and Laureth-9 [101] (Table 2). The patient developed generalized urticaria, dizziness, and dyspnea after using a topical Betadine solution (containing laureth-9), anaphylaxis after swallowing an antihistamine cough syrup containing macrogol 6000 (GripaNait), itchy maculopapular rash caused by contact with moisturizing skin creams containing PEG-75 and PEG-100, generalized urticaria with soap, and swelling of the gums and tongue after using a toothpaste. The results of SPTs to GripaNait, Betadine gel and solution, and PEGs were positive. BATs were positive to all PEG-containing products used by the patient. SPTs and BATs were also positive for poloxamer 407 and PS80, as well as cetirizine and doxylamine antihistamine tablets and ebastine tablets and solution, containing PEG. With the latter excipients, the authors wanted to demonstrate cross-reactivity with other structural analogues, as well as hypersensitivity to other drugs (antihistamines) that contained PEG, even if they were not involved in the multiple reactions observed.

\section{PVP}

- Itching of the soles, generalized hives and swelling of the face after the first topical use of Betadine on an arm wound: SPTs were positive to Betadine and PVP. sIgE to PVP was demonstrated by ELISA [102].

- IHRs with unrelated products due to PVP [103] (Table 2): Anaphylaxis was described after vaginal application of PVP-iodine (Isodine) for a medical examination in a patient who had previously experienced several episodes of contact urticaria with hair care products. Analysis of the shampoo and the permanent wave solution used revealed that both contained PVP. SPTs were positive to Isodine, PVP, and the hair care products used by the patient.

\section{Throat Lozenges}

\section{Lysozyme}

IHRs with unrelated products due to lysozyme [104] (Table 2): Reactions reported with a lysozyme-containing tablet (Lizipaina) and the ingestion of cured cheese or raw egg. The difference in the composition of the nontolerated cheeses was the presence of lysozyme. SPTs to commercial extracts of egg white and lysozyme were positive. 


\section{Ultrasound Gels}

\section{PEG/Macrogol}

Anaphylaxis after transvaginal ultrasound has been attributed to the lubricating gel, which contained PEG [105]. SPTs were positive to the gel and to PEG- 8000 .

\section{Vaccines}

Few cases of sensitization to vaccine ingredients have been described; however, excipients and manufacturing residues should be taken into consideration [106].

\section{Aluminum}

IHRs have been reported to unrelated products due to aluminum [107] (Table 2). Anaphylaxis occurred after administration of an aluminum-containing tetanus vaccine (Tetavax), as did urticaria after changing a colchicum treatment to an aluminum-containing pharmaceutical form. The results of SPTs to aluminum were positive; that of an OCT with the aluminum-free colchicum preparation was negative.

\section{Gelatin}

IHRs to unrelated products due to gelatin, have been reported [108,109] (Table 2), as follows:

- Anaphylaxis with measles, mumps, and rubella (MMR) vaccine (gelatin-containing), and throat pruritus and tongue swelling after eating gelatin: SPTs and SIgE to the vaccine and gelatin were positive [108].

- Anaphylaxis after injection of chickenpox vaccine (gelatin-containing) in a patient who had previously experienced an allergic reaction to gelatinous candies: sIgE to pork gelatin was positive [109].

- Anaphylaxis after injection of chickenpox (gelatincontaining) and hepatitis A vaccines: SPTs were positive to gelatin and the chickenpox vaccine [110].

\section{PS80}

Anaphylaxis has been reported after the third administration of the human papillomavirus vaccine Gardasil, which contains PS80 [111]. The results of IDT to Gardasil and SPT to PS80 were positive. However, those of BAT and sIgE to PS80 were negative.

\section{Conclusions}

The significant number of reported cases of IHRs properly diagnosed as being caused by excipients highlights the need for all the excipients contained in the formulation of a medication to be listed on the package insert, thus obviating the need to request the compound list from the manufacturer. Adequate labeling and standardization of excipient nomenclature and agents potentially involved in each reaction, sometimes in multiple unrelated drugs, would avoid confusion and facilitate diagnosis and implementation of safe avoidance strategies to prevent future reactions in sensitized patients, once allergy to active ingredients has been excluded.
Finally, it would be interesting to provide patients who are allergic to excipients with a list of commercial products that contain the trigger component and alternatives, since they may be present in drugs the patient could need in the future, and recommend that he/she carry an emergency kit with autoinjectable epinephrine.

\section{Funding}

The authors declare that no funding was received for the present study.

\section{Conflicts of Interest}

The authors declare that they have no conflicts of interest.

\section{References}

1. European Medicines Agency. Doc. Ref. EMEA/CHMP/ QWP/396951/2006. London, 19 June 2007.

2. Audicana Berasategui MT, Barasona Villarejo MJ, Corominas Sánchez M, De Barrio Fernández M, García Avilés MC, García Robaina JC, et al. Potential hypersensitivity due to the food or food additive content of medicinal products in Spain. J Investig Allergol Clin Immunol. 2011;21:496-506.

3. Kelso JM. Potential food allergens in medications. J Allergy Clin Immunol. 2014;133:1509-18.

4. Barbaud A. Place of excipients in systemic drug allergy. Immunol Allergy Clin N Am. 2014;34:671-9.

5. Lamb JD, Keogh JAM. Anaphylactoid reaction to mannitol. Can Anaesth Soc J. 1979;26:435-6.

6. McNeill IY. Hypersensitivity reaction to mannitol. Drug Intell Clin Pharm. 1985; 19:552-3.

7. Schmid P, Wuthrich B. Perianhesthetic anaphylactoid shock due to mannitol. Allergy. 1992;47:61-2.

8. Findlay SR, Kagey-Sobota A, Lichtenstein LM. In vitro basophil histamine release induced by mannitol in a patient with mannitol induced anaphylactoid reaction. J Allergy Clin Immunol. 1984;73:578-83.

9. Calogiuri GF, Muratore L, Nettis E, Casto AM, Di Leo E, Vacca A. Immediate-type hypersensitivity reaction to Mannitol as drug excipient (E421): a case report. Eur Ann Allergy Clin Immunol. 2015;47:99-102.

10. Hegde VL, Venkatesh YP. Anaphylaxis to excipient mannitol: evidence for an immunoglobulin E-mediated mechanism. Clin Exp Allergy. 2004;34:1602-9.

11. Rönnau AC, Wulferink M, Gleichmann E, Unver $E$, Ruzicka $T$, Krutmann J, et al. Anaphylaxis to polyvinylpyrrolidone in an analgesic preparation. Br J Dermatol. 2000;143:1055-8.

12. Wenande $E$, Garvey LH. Immediate-type hypersensitivity to polyethylene glycols: a review. Clin Exp Allergy. 2016;46:907-22.

13. Henning T. Polyethylene glycols (PEGs) and the pharmaceutical industry. Fine, Specialty \& Performance Chemicals. Pharmachem. 2002;1:57-9.

14. Hyry H, Vuorio A, Varjonen E, Skyttä J, Mäkinen-Kiljunen S. Two cases of anaphylaxis to macrogol 6000 after ingestion of drug tablets. Allergy. 2006;61:1021.

15. Badiu I, Guida G, Heffler E, Rolla G. Multiple Drug Allergy Due to Hypersensitivity to Polyethylene Glycols of Various Molecular Weights. J Investig Allergol Clin Immunol. 2015;25:368-9. 
16. Kim YN, Kim JY, Kim JW, Kim JH, Kim HI, Yune S, et al. The Hidden Culprit: A Case of Repeated Anaphylaxis to Cremophor. Allergy Asthma Immunol Res. 2016;8:174-7.

17. Pantín C, Letellez J, Calzas J, Mohedano E. Indirect identification of hypersensitivity reaction to etoposide mediated by polysorbate 80. Farm Hosp. 2018;42:27-8.

18. Muroi N, Nishibori M, Fujii T, Yamagata M, Hosoi S, Nakaya N, et al. Anaphylaxis from the carboxymethylcellulose component of barium sulfate suspension. N Engl J Med. 1997;337:12757.

19. Dumond P, Franck P, Morisset M, Sainte Laudy J, Kanny G, Moneret-Vautrin DA. Pre-lethal anaphylaxis to carboxymethylcellulose confirmed by identification of specific IgE-review of the literature. Eur Ann Allergy Clin Immunol. 2009;41:171-6.

20. Tarlo SM, Dolovich J, Listgarten C. Anaphylaxis to carrageenan: a pseudo-latex allergy. J Allergy Clin Immunol. 1995;95:9336.

21. Oyarzabal NA, Areso NL, Belar NB, Popolizio IG, Arregui AV, Vallejo OVB. Anaphylactic shock due to allergy to macrogol 4000 contained in SonoVue. Case Reports in Clinical Medicine. 2017:6:143-7.

22. Moneret-Vautrin DA, Mata E, Gerard H, Trechot M. Probable allergy to polyvidon, responsible for a reaction to iodinated contrast medium: a case of asthma after hysterosal pingography. Allerg Immunol (Paris). 1989;21:196;198-9.

23. Lukawska J, Mandaliya D, Chan AWE, Foggitt A, Bidder T, Harvey J, et al. Anaphylaxis to trometamol excipient in gadolinium-based contrast agents for clinical imaging. J Allergy Clin Immunol Pract. 2019;7:1086-7.

24. Li PH, Wagner A, Thomas I, Watts TJ, Rutkowski R, Rutkowski K. Steroid Allergy: Clinical Features and the Importance of Excipient Testing in a Diagnostic Algorithm. J Allergy Clin Immunol Pract. 2018;6:1655-61.

25. Patel A, Bahna SL. Immediate hypersensitivity reactions to corticosteroids. Ann Allergy Asthma Immunol. 2015;115:17882.

26. Calogiuri G, Garvey LH, Romita P, Macchia L, Foti C. Hypersensitivity Reactions from Excipients in Systemic Glucocorticoid Formulations. Antiinflamm Antiallergy Agents Med Chem. 2016;15:91-100.

27. Beaudouin E, Kanny G, Gueant JL, Moneret-Vautrin DA. Anaphylaxis caused by carboxymethylcellulose: report of 2 cases of shock from injectable corticoids. Allerg Immunol (Paris). 1992;24:333-5.

28. Patterson DL, Yunginger JW, Dunn WF, Jones RT, Hunt LW. Anaphylaxis induced by the carboxymethylcellulose component of injectable triamcinolone acetonide suspension (Kenalog). Ann Allergy Asthma Immunol. 1995;74:163-6.

29. Meyer MW, Zachariae C, Garvey LH. Anaphylactic shock after intradermal injection of corticosteroid. Ugeskr Laeger. 2015;19;177:V10140532.

30. Schuster C, Wüthrich B, Hartmann K, Kuhn M. Anaphylaxis to E466. Allergy. 2000;55:303-4.

31. Bigliardi PL, Izakovic J, Weber JM, Bircher AJ. Anaphylaxis to the carbohydrate carboxymethylcellulose in parenteral corticosteroid preparations. Dermatology. 2003;207:100-3.

32. Montoro J, Valero A, Elices A, Rubira N, Serra-Baldrich E, Amat $P$, et al. Anaphylactic shock after intra-articular injection of carboxymethylcellulose. Allergol Immunopathol (Madr). 2000;28:332-3.

33. Venturini M, Lobera T, del Pozo MD, González I, Blasco A Immediate hypersensitivity to corticosteroids. J Investig Allergol Clin Immunol. 2006;16:51-6.

34. Laing ME, Fallis $B$, Murphy GM. Anaphylactic reaction to intralesional corticosteroid injection. Contact Dermatitis. 2007; 57:132-3.

35. Rival-Tringali AL, Gunera-Saad N, Berard F, Chambost V, Roziere A, Guillot-Pouget I, et al. Tolérance de la carboxymethylcellulose par voie orale chez deux malades ayant developpé une anaphylaxie á la carboxymethylcellulose injectable. Ann Dermatol Venereol. 2008;135:402-6.

36. Muroi N, Mori S, Ono S, Takahashi HK, Fujii T, Hosoi S, et al. Allergy to carboxymethylcellulose. Allergy. 2002;57:1212-3.

37. Field S, Falvey E, Barry J, Bourke J. Type 1 hypersensitivity reaction to carboxymethylcellulose following intra-articular triamcinolone injection. Contact Dermatitis. 2009;61:302-3.

38. Spoerl D, Scherer K, Bircher AJ. Contact urticaria with systemic symptoms due to hexylene glycol in a topical corticosteroid: case report and review of hypersensitivity to glycols. Dermatology. 2010;220:238-42.

39. Eda A, Sugai $K$, Shioya $H$, Fujitsuka $A$, Ito $S$, Iwata $T$, et al. Acute allergic reaction due to milk proteins contaminating lactose added to corticosteroid for injection. Allergol Int. 2009;58:137-9.

40. Nowak-Wegrzyn A, Shapiro GG, Beyer K, Bardina L, Sampson HA. Contamination of dry powder inhalers for asthma with milk proteins containing lactose. J Allergy Clin Immunol. 2004;113:558-60.

41. Andrade ALMB, Riccetto AGL, Vilela MMDS, de Oliveira DN, Catharino RR, Nolasco da Silva MT. Anaphylactic reaction to galactose-derived oligosaccharide residues from lactose used as a drug excipient. Pediatr Allergy Immunol. 2018;29:20710.

42. Sohy C, Vandenplas O, Sibille Y. Usefulness of oral macrogol challenge in anaphylaxis after intra-articular injection of corticosteroid preparation. Allergy. 2008;63:478-9.

43. Bordere A, Stockman A, Boone B, Franki AS, Coppens MJ, Lapeere $\mathrm{H}$, et al. A case of anaphylaxis caused by macrogol 3350 after injection of a corticosteroid. Contact Dermatitis. 2012;67:375-85.

44. Wenande EC, Skov PS, Mosbech H, Poulsen LK, Garvey LH. Inhibition of polyethylene glycol-induced histamine release by monomeric ethylene and diethylene glycol: a case of probable polyethylene glycol allergy. J Allergy Clin Immunol. 2013;131:1425-7.

45. Brandt N, Garvey LH, Bindslev-Jensen U, Kjaer HF, BindslevJensen C, Mortz CG. Three cases of anaphylaxis following injection of a depot corticosteroid with evidence of $\mathrm{lgE}$ sensitization to macrogols rather than the active steroid. Clin Transl Allergy. 2017;7:2

46. Dewachter P, Mouton-Faivre C. Anaphylaxis to macrogol 4000 after a parenteral corticoid injection. Allergy. 2005;60:705-6.

47. Palacios Castaño MI, Venturini Díaz M, Lobera Labairu $T$, González Mahave I, Del Pozo Gil MD, Blasco Sarramián A. Anaphylaxis Due to the Excipient Polysorbate 80. J Investig Allergol Clin Immunol. 2016;26:394-6. 
48. Gonzalo Garijo MA, Durán Quintana JA, Bobadilla González P, Máiquez Asuero P. Anaphylactic shock following povidone. Ann Pharmacother. 1996;30:37-40.

49. Michavila-Gomez AV, Moreno-Palanques MA, Ferrer-Vazquez $M$, Ferriols-Leisart R, Bartolomé B. Anaphylactic reaction to povidone secondary to drug ingestion in a young child. Allergol Immunopathol (Madr). 2012;40:259-61.

50. Coloe J, Zirwas MJ. Allergens in corticosteroid vehicles. Dermatitis. 2008;19:38-42.

51. Warshaw EM, Botto NC, Maibach HI, Fowler JF Jr, Rietschel RL, Zug KA, et al. Positive PT reactions to propylene glycol: a retrospective cross-sectional analysis from the North American Contact Dermatitis Group, 1996 to 2006. Dermatitis. 2009;20:14-20.

52. Co-Minh HB, Demoly P, Guillot B, Raison-Peyron N. Anaphylactic shock after oral intake and contact urticaria due to polyethylene glycols. Allergy. 2007;62:92-3.

53. Steele RH, Limaye S, Cleland B, Chow J, Suranyi MG. Hypersensitivity reactions to the polysorbate contained in recombinant erythropoietin and darbepoetin. Nephrology. 2005:10:317-20.

54. Ghazavi MK, Johnston GA. Insulin allergy. Clin Dermatol. 2011;29:300-5.

55. Wheeler BJ, Taylor BJ. Successful management of allergy to the insulin excipient metacresol in a child with type 1 diabetes: a case report. J Med Case Rep. 2012;6:263.

56. Hagedorn HC, Jensen BN, Kraup NB, Wodstrup I. Protamine insulinate. JAMA. 1936;106:177-80.

57. Sanchez MB, Paolillo M, Chacon RS, Camejo M. Protamine as a cause of generalized allergic reactions to NPH insulin. Lancet. 1982;1:1243.

58. Dykewicz MS, Kim HW, Orfan N, Yoo TJ, Lieberman P. Immunologic analysis of anaphylaxis protamine component in neutral protamine Hagedorn human insulin. J Allergy Clin Immunol. 1994;93:117-25.

59. Bollinger ME, Hamilton RG, Wood RA. Protamine allergy as a complication of insulin hypersensitivity: A case report. J Allergy Clin Immunol. 1999;104:462-5.

60. Bruni B, Campana M, Gamba S, Grassi G, Blatto A. A generalized allergic reaction due to zinc in insulin preparation. Diabetes Care. 1985;8:201.

61. Ben Ammar I, Ksouri H, Trabelsi N, Mellouli F, Ben Mami F, Dakhli $S$, et al. Generalized allergy due to zinc in insulin treated with zinc-free insulin. Acta Diabetol. 2012;49:239-41.

62. Gin H, Aubertin J. Generalized allergy due to zinc and protamine in insulin preparation treated with insulin pump. Diabetes Care. 1987;10:789-90.

63. Shah S, Prematta T, Adkinson NF, Ishmael FT. Hypersensitivity to polyethylene glycols. J Clin Pharmacol. 2013;53:352-5.

64. Gachoka D. Polyethylene Glycol (PEG)-Induced Anaphylactic Reaction During Bowel Preparation. ACG Case Rep J. 2015:2:216-7.

65. Antón Gironés M, Roan Roan J, de la Hoz B, Sánchez Cano M. Immediate allergic reactions by polyethylene glycol 4000: two cases. Allergol Immunopathol (Madr). 2008;36:110-2.

66. Pizzimenti S, Heffler E, Gentilcore E, Raie A, Bussolino C, Nebiolo $F$, et al. Macrogol hypersensitivity reactions during cleansing preparation for colon endoscopy. J Allergy Clin Immunol Pract. 2014;2:353-4.
67. Castanedo-Tardan MP, González ME, Connelly EA, Giordano $\mathrm{K}$, Jacob SE. Systematized contact dermatitis and montelukast in an atopic boy. Pediatr Dermatol. 2009;26:739-43.

68. Larramendi CH, Marco FM, García-Abujeta JL, Mateo M, de la Vega A, Sempere JM. Acute allergic reaction to an iron compound in a milk-allergic patient. Pediatr Allergy Immunol. 2006;17:230-3.

69. Caballero ML, Lluch-Bernal M, Vilà-Nadal G, Lluncor M, Quirce S. IgE-Mediated Anaphylaxis Induced by Macrogol 6000. J Investig Allergol Clin Immunol. 2016;26:398-400.

70. Price KS, Hamilton RG. Anaphylactoid reactions in two patients after omalizumab administration after successful long-term therapy. Allergy Asthma Proc. 2007;28:313-9.

71. Perino E, Freymond N, Devouassoux G, Nicolas JF, Berard F. Xolair-induced recurrent anaphylaxis through sensitization to the excipient polysorbate. Ann Allergy Asthma Immunol. 2018;120:664-6.

72. Yamasuji $Y$, Higashi $Y$, Sakanoue M, Katsue $H$, Kawai $K$, Arai $\mathrm{N}$, et al. A case of anaphylaxis caused by polyethylene glycol analogues. Contact Dermatitis. 2013;69:183-5.

73. Pérez-Pérez L, García-Gavín J, Piñeiro B, Zulaica A. Biologicinduced urticaria due to polysorbate 80: usefulness of prick test. Br J Dermatol. 2011;164:1119-20.

74. Singh SK, Mahler HC, Hartman C, Stark CA. Are Injection Site Reactions in Monoclonal Antibody Therapies Caused by Polysorbate Excipient Degradants? J Pharm Sci. 2018;107:2735-41.

75. Artesani MC, Donnanno S, Cavagni G, Calzone L, D'Urbano L. Egg sensitization caused by immediate hypersensitivity reaction to drug-containing lysozyme. Ann Allergy Asthma Immunol. 2008;101:105.

76. Bommarito L, Mietta S, Nebiolo F, Geuna M, Rolla G. Macrogol hypersensitivity in multiple drug allergy. Ann Allergy Asthma Immunol. 2011;107:542-3.

77. Hebron BS, Hebron HJ. Aspirin sensitivity: acetylsalicylate or excipients. Intern Med J. 2009;39:546-9.

78. Ventura MT, Viola M, Gaeta F, Di Leo E, Buquicchio R, Romano A. Hypersensitivity reactions to ophthalmic products. Curr Pharm Des. 2006;12:3401-10.

79. Anderson D, Faltay B, Haller NA. Anaphylaxis with use of eyedrops containing benzalkonium chloride preservative. Clin Exp Optom. 2009:92:444-6.

80. Carbonell A, Miralles JC, Escudero Al, Martínez A, Pineda F, Aldana D. Urticaria-angioedema due to carboxymethylcellulose eye drops. J Investig Allergol Clin Immunol. 2012;22:288-9.

81. Liccioli G, Mori F, Barni S, Pucci N, Novembre E. Anaphylaxis to Polyvinylpyrrolidone in Eye Drops Administered to an Adolescent. J Investig Allergol Clin Immunol. 2018;28:263-5.

82. Trissel LA. Handbook on injectable drugs. 2nd ed. Washington, D.C.: American Society of Hospital Pharmacists, 1980.

83. Grant JA, Bilodeau PA, Guernsey BG, Gardner FH. Unsuspected benzyl alcohol hypersensitivity. N Engl J Med. 1982;306:108.

84. Turvey SE, Cronin B, Arnold AD, Twarog FJ, Dioun AF. Adverse reactions to vitamin $\mathrm{B} 12$ injections due to benzyl alcohol sensitivity: successful treatment with intranasal cyanocobalamin. Allergy. 2004;59:1023-4.

85. Wilson JP, Solimando DA Jr, Edwards MS. Parenteral benzyl alcohol-induced hypersensitivity reaction. Drug Intell Clin Pharm. 1986;20:689-91. 
86. Garvey LH. Old, New and Hidden Causes of Perioperative Hypersensitivity. Curr Pharm Des. 2016;22:6814-24.

87. Hepner DL, Castells MC. Anaphylaxis during the perioperative period. Anesth Analg. 2003;97:1381-95.

88. Khoriaty E, McClain C, Permaul P, Smith ER, Rachid R. Intraoperative anaphylaxis induced by the gelatin component of thrombin-soaked Gelfoam in a pediatric patient. Ann Allergy Asthma Immunol. 2012;108:209-10.

89. Robbins KA, Keet CA. Intraoperative anaphylaxis likely due to Gelfoam in a pediatric patient undergoing liver biopsy. Ann Allergy Asthma Immunol. 2015;114:531-3.

90. Spencer HT, Hsu JT, McDonald DR, Karlin LI. Intraoperative anaphylaxis to gelatin in topical hemostatic agents during anterior spinal fusion: a case report. Spine J. 2012;12:e1-6.

91. Agarwal NS, Spalding C, Nassef M. Life-threatening intraoperative anaphylaxis to gelatin in Floseal during pediatric spinal surgery. J Allergy Clin Immunol Pract. 2015;3:110-1.

92. Luhmann SJ, Sucato DJ, Bacharier L, Ellis A, Woerz C. Intraoperative anaphylaxis secondary to intraosseous gelatin administration. J Pediatr Orthop. 2013;33:e58-60.

93. Uyttebroek A, Sabato V, Bridts CH, De Clerck LS, Ebo DG. Anaphylaxis to succinylated gelatin in a patient with a meat allergy: galactose- $\alpha(1,3)$-galactose $(\alpha$-gal) as antigenic determinant. J Clin Anesth. 2014;26:574-6.

94. Munk SJ, Heegaard S, Mosbech H, Garvey LH. Two episodes of anaphylaxis following exposure to hydroxypropyl methylcellulose during cataract surgery. J Cataract Refract Surg. 2013;39:948-51.

95. Jain SS, Green S, Rose M. Anaphylaxis following intravenous paracetamol: the problem is the solution. Anaesth Intensive Care. 2015:43:779-81.

96. Wenande E, Kroigaard M, Mosbech H, Garvey LH. Polyethylene glycols (PEG) and related structures: overlooked allergens in the perioperative setting. A A Case Rep. 2015;4:61-4.

97. Le Pabic F, Sainte-Laudy J, Blanchard N, Moneret-Vautrin DA. First case of anaphylaxis to iodinated povidone. Allergy. 2003;58:826-7.

98. Caballero MR, Lukawska J, Dugué P. A hidden cause of perioperative anaphylaxis. J Investig Allergol Clin Immunol 2010;20:353-4

99. Singh-Joy SD, McLain VC. Safety assessment of poloxamers $101,105,108,122,123,124,181,182,183,184,185,188$, $212,215,217,231,234,235,237,238,282,284,288,331$, $333,334,335,338,401,402,403$, and 407, poloxamer 105 benzoate, and poloxamer 182 dibenzoate as used in cosmetics. Int J Toxicol. 2008; 27(Suppl. 2):93-128.

100. Carbonell A, Escudero Al, Miralles JC, Gonzalez A, Navarro C, Cardona P, et al. Anaphylaxis due to Poloxamer 238. J Investig Allergol Clin Immunol. 2018;28:419-20.

101. Jover Cerdá V, Rodríguez Pacheco R, Doménech Witek J, Marco de la Calle FM, de la Sen Fernández ML. Immediate hypersensitivity to polyethylene glycols in unrelated products: when standardization in the nomenclature of the components of drugs, cosmetics, and food becomes necessary. Allergy Asthma Clin Immunol. 2019 Feb 19;15:9. doi: 10.1186/ s13223-019-0327-4. eCollection 2019.

102. López Sáez MP, de Barrio M, Zubeldia JM, Prieto A, Olalde S, Baeza ML. Acute IgE-mediated generalized urticariaangioedema after topical application of povidone-iodine. Allergol Immunopathol (Madr). 1998;26:23-6.

103. Adachi A, Fukunaga A, Hayashi K, Kunisada M, Horikawa T. Anaphylaxis to polyvinylpyrrolidone after vaginal application of povidone-iodine. Contact Dermatitis. 2003;48(3):133-6.

104. Pérez-Calderón R, Gonzalo-Garijo MA, Lamilla-Yerga A, Mangas-Santos R, Moreno-Gastón I. Recurrent angioedema due to lysozyme allergy. J Investig Allergol Clin Immunol. 2007; 17:264-6.

105. Jakubovic BD, Saperia C, Sussman GL. Anaphylaxis following a transvaginal ultrasound. Allergy Asthma Clin Immunol. 2016;12:3

106. Barbaud A, Deschildre A, Waton J, Raison-Peyron N, Tréchot P. Hypersensitivity and vaccines: an update. Eur J Dermatol. 2013;23:135-41.

107. Kutlu A, Ucar R, Aydin E, Arslan S, Calıskaner AZ. Could aluminum be a new hidden allergen in type 1 hypersensitivity reactions when used as a drug additive? Postepy Dermatol Alergol. 2016;33:243-5.

108. Kelso JM, Jones RT, Yunginger JW. Anaphylaxis to measles, mumps, and rubella vaccine mediated by $\lg \mathrm{E}$ to gelatin. J Allergy Clin Immunol. 1993;91:867-72.

109. Zuo L. A child with gelatin hypersensitivity and anaphylaxis to both jelly beans and MMR/varicella vaccines. 2009 annual meeting of the American college of Allergy, Asthma and Immunology poster 3 (http:/www.acaai.org).

110. Toh J, Jariwala SP, Hudes G, Rosenstreich D. Anaphylaxis after varicella vaccination. 2009 annual meeting of the American college of Allergy, Asthma and Immunology, poster 304 (http:/ www.acaai.org).

111. Badiu I, Geuna M, Heffler E, Rolla G. Hypersensitivity reaction to human papillomavirus vaccine due to polysorbate 80 . BMJ Case Rep. 2012;2012.

\section{- Manuscript received July 17, 2019; accepted for publication December 16, 2019.}

\section{- María Luisa Caballero}

Department of Allergy

Hospital La Paz Institute for Health Research (IdiPAZ)

Paseo de la Castellana, 261

28046 Madrid, Spain

E-mail: mlcsoto@hotmail.com 